\title{
A fixed point theorem by altering distance technique in complete metric spaces
}

\author{
A. Amini-Harandi and A. Petrusel
}




\title{
A FIXED POINT THEOREM BY ALTERING DISTANCE TECHNIQUE IN COMPLETE METRIC SPACES
}

\author{
A. AMINI-HARANDI AND A. PETRUŞEL
}

Received 18 September, 2012

\begin{abstract}
In this paper, we present a fixed point theorem for a new type of contractive mappings. Our main result extends and unifies some well-known results in the literature.

2000 Mathematics Subject Classification: 47H10; 54H25

Keywords: fixed point, Banach contraction principle, contractive type mapping, altering distance approach
\end{abstract}

\section{INTRODUCTION}

Banach contraction principle play an important role in several branches of mathematics. For instances, it has been used to study the existence of solutions of nonlinear Volterra and Fredholm integral equations, nonlinear integro-differential equations in Banach spaces and to prove the convergence of algorithms in computational mathematics. Because of its importance in mathematics, Banach contraction principle has been extended in many different directions, see [1-15] and references therein.

In [10] Khan et al. proved the following fixed point theorem.

Theorem 1 ([10]). Let $(X, d)$ be a complete metric space, and let $T: X \rightarrow X$ be a mapping satisfying

$$
\psi(d(T x, T y)) \leq k \psi(d(x, y)),
$$

for each $x, y \in X$ and for some $k \in[0,1)$ where $\psi:[0, \infty) \rightarrow[0, \infty)$ is a continuous and non-decreasing function such that $\psi(t)=0$ if and only if $t=0$. Then $T$ has a unique fixed point $\bar{x} \in X$ such that $\lim _{n \rightarrow \infty} T^{n} x=\bar{x}$, for each $x \in X$.

Another generalization of the contraction principle was suggested by Alber and Guerre-Delabriere [1] in Hilbert spaces. Rhoades [15] has shown that the result that Alber and Guerre-Delabriere proved in [1] is also valid in complete metric spaces. We state the result of Rhoades in the following.

This work was possible with the financial support of a grant of the Romanian National Authority for Scientific Research, CNCS-UEFISCDI, project number PN-II-ID-PCE-2011-3-0094. 
Theorem 2 ([15]). Let $(X, d)$ be a complete metric space. Let $T: X \rightarrow X$ be a mapping which satisfies

$$
d(T x, T y) \leq d(x, y)-\phi(d(x, y))
$$

for each $x, y \in X$, where $\phi:[0, \infty) \rightarrow[0, \infty)$ is a continuous and non-decreasing function such that $\phi(t)=0$ if and only if $t=0$. Then $T$ has a unique fixed point $\bar{x} \in X$ such that $\lim _{n \rightarrow \infty} T^{n} x=\bar{x}$, for each $x \in X$.

In fact, Alber and Guerre-Delabriere assumed an additional condition on $T$ which is $\lim _{t \rightarrow \infty} \phi(t)=\infty$. Notice that Rhoades [15] obtained the result presented in Theorem 2 without using this particular assumption.

In 2008 Dutta et al. [6] proved the following generalization of Banach contraction mapping principle which includes the generalizations presented in Theorems 1 and 2.

Theorem 3 ([6]). Let $(X, d)$ be a complete metric space, and let $T: X \rightarrow X$ be a mapping satisfying

$$
\psi(d(T x, T y)) \leq \psi(d(x, y))-\phi(d(x, y)),
$$

for each $x, y \in X$, where $\psi, \phi:[0, \infty) \rightarrow[0, \infty)$ are continuous and non-decreasing function such that $\psi(t)=\phi(t)=0$ if and only if $t=0$. Then $T$ has a unique fixed point $\bar{x} \in X$ such that $\lim _{n \rightarrow \infty} T^{n} x=\bar{x}$, for each $x \in X$.

The purpose of this paper is to present a new generalization of the Banach contraction principle in terms of altering distances. Our theorem unifies and extends some well-known results in the literature including the above theorems.

\section{MAin Results}

We are ready to state our main result.

Theorem 4. Let $(X, d)$ be a complete metric space and let $T: X \rightarrow X$ be a mapping satisfying

$$
u(d(T x, T y)) \leq v(d(x, y)), \text { for each } x, y \in X,
$$

where $u, v:[0, \infty) \rightarrow[0, \infty), v(t)<u(t)$ for each $t>0$ and $u(0)=v(0)=0$. Assume either one of the following assumptions holds:

(a) $u$ and $v$ are continuous and if $\left\{u\left(x_{n}\right)\right\}$ be a non-increasing sequence then $\left\{x_{n}\right\}$ is bounded;

(b) $u$ is increasing, continuous, $u^{-1}$ is continuous and $v$ is continuous from the right;

(c) $u$ is increasing, continuous, $v$ is continuous at $0, \liminf _{t \rightarrow \infty}\left(t-u^{-1}(v(t))\right)>0$ and $\limsup _{s \rightarrow r} v(s)<v(r)$ for each $r>0$.

Then $T$ has a unique fixed point $\bar{x} \in X$ such that $\lim _{n \rightarrow \infty} T^{n} x=\bar{x}$, for each $x \in X$. 
Proof. For any $x_{0} \in X$, we construct the sequence $\left\{x_{n}\right\}$ by $x_{n}=T x_{n-1}$ for $n \in \mathbb{N}$. From our assumption on $T$, we have

$$
u\left(d\left(x_{n}, x_{n+1}\right)\right) \leq v\left(d\left(x_{n-1}, x_{n}\right)\right), \text { for each } n \in \mathbb{N} .
$$

Since

$$
v\left(d\left(x_{n-1}, x_{n}\right)\right) \leq u\left(d\left(x_{n-1}, x_{n}\right)\right), \text { for each } n \in \mathbb{N}
$$

then from (2.1) and (2.2), we get

$$
u\left(d\left(x_{n}, x_{n+1}\right)\right) \leq v\left(d\left(x_{n-1}, x_{n}\right)\right) \leq u\left(d\left(x_{n-1}, x_{n}\right)\right) \text {, for each } n \in \mathbb{N} .
$$

From (2.3), we deduce that $\left\{u\left(d\left(x_{n}, x_{n+1}\right)\right)\right\}$ is a non-negative non-increasing sequence and consequently there exists $r \geq 0$ such that

$$
\lim _{n \rightarrow \infty} u\left(d\left(x_{n}, x_{n+1}\right)\right)=r \text {. }
$$

We shall show that

$$
\lim _{n \rightarrow \infty} d\left(x_{n}, x_{n+1}\right)=0 .
$$

Assume first that (a) holds. Then $\left\{d\left(x_{n}, x_{n+1}\right)\right\}$ is a bounded subsequence. On the contrary, assume that

$$
\lim _{k \rightarrow \infty} d\left(x_{n_{k}}, x_{n_{k}+1}\right)=s>0,
$$

for some subsequence $\left\{x_{n_{k}}\right\}$ of $\left\{x_{n}\right\}$. Since $u$ and $v$ are continuous then from (2.3), (2.4) and (2.6), we have

$$
u(s)=\lim _{k \rightarrow \infty} u\left(d\left(x_{n_{k}}, x_{n_{k}+1}\right)\right)=\lim _{k \rightarrow \infty} v\left(d\left(x_{n_{k}}, x_{n_{k}+1}\right)\right)=v(s),
$$

and so $s=0$, a contradiction. Thus (2.5) holds.

If (b) holds, since $u$ is increasing and $\left\{u\left(d\left(x_{n}, x_{n+1}\right)\right)\right\}$ is non-increasing then we get that the sequence $\left\{d\left(x_{n}, x_{n+1}\right)\right\}$ is non-increasing and consequently there exists $s_{0} \geq 0$ such that $\lim _{n \rightarrow \infty} d\left(x_{n}, x_{n+1}\right)=s_{0}$. Since $u$ is continuous from (2.4) we deduce that

$$
0=\lim _{n \rightarrow \infty} u\left(d\left(x_{n}, x_{n+1}\right)\right)=u\left(s_{0}\right)
$$

and so $s_{0}=0$. Thus (2.5) holds in any case.

We next prove that $\left\{x_{n}\right\}$ is a Cauchy sequence. If possible, let $\left\{x_{n}\right\}$ be not a Cauchy sequence. Then there exists $\epsilon>0$ for which we can find subsequences $\left\{x_{m}(k)\right\}$ and $\left\{x_{n}(k)\right\}$ of $\left\{x_{n}\right\}$ with $n(k)>m(k)>k$ such that

$$
d\left(x_{m(k)}, x_{n(k)}\right) \geq \epsilon \text {, for each } k \in \mathbb{N} .
$$

Further, corresponding to $m(k)$, we can choose $n(k)$ in such a way that it is the smallest integer with $n(k)>m(k)$ and satisfying (2.7). Then

$$
d\left(x_{m(k)}, x_{n(k)-1}\right)<\epsilon .
$$

Then, we have

$\epsilon \leq d\left(x_{m(k)}, x_{n(k)}\right) \leq d\left(x_{m(k)}, x_{n(k)-1}\right)+d\left(x_{n(k)-1}, x_{n(k)}\right)<\epsilon+d\left(x_{n(k)-1}, x_{n(k)}\right)$. 
Letting $k \rightarrow \infty$ and using (2.5),

$$
\lim _{k \rightarrow \infty} d\left(x_{m(k)}, x_{n(k)}\right)=\epsilon
$$

Again,

$$
d\left(x_{n(k)}, x_{m(k)}\right) \leq d\left(x_{n(k)}, x_{n(k)-1}\right)+d\left(x_{n(k)-1}, x_{m(k)-1}\right)+d\left(x_{m(k)-1}, x_{m(k)}\right),
$$

and

$$
d\left(x_{n(k)-1}, x_{m(k)-1}\right) \leq d\left(x_{n(k)-1}, x_{n(k)}\right)+d\left(x_{n(k)}, x_{m(k)}\right)+d\left(x_{m(k)}, x_{m(k)-1}\right) .
$$

Letting $k \rightarrow \infty$ in the above two inequalities and using (2.5) and (2.9), we get

$$
\lim _{k \rightarrow \infty} d\left(x_{n(k)-1}, x_{m(k)-1}\right)=\epsilon .
$$

Now, assume (a) holds. Let $0<\alpha<1$. Since $u$ is continuous then from (2.1) and (2.9) there exists $K$ such that

$$
\alpha u(\epsilon) \leq u\left(d\left(x_{m(k)}, x_{n(k)}\right)\right) \leq v\left(d\left(x_{m(k)-1}, x_{n(k)-1}\right)\right),
$$

for each $k \geq K$. Letting $k \rightarrow \infty$ and using (2.9) and (2.10), we obtain $\alpha u(\epsilon) \leq v(\epsilon)$. Since $0<\alpha<1$ is arbitrary, we get

$$
u(\epsilon) \leq v(\epsilon),
$$

which is a contradiction if $\epsilon>0$ and so $\left\{x_{n}\right\}$ is a Cauchy sequence.

Now, assume that (b) holds. Since $u$ is increasing then from our assumption on $T$, we get

$$
d(T x, T y) \leq u^{-1}(v(d(x, y))) \leq d(x, y), \text { for each } x, y \in X .
$$

From (2.11) and for each $k \in \mathbb{N}$, we have

$$
\begin{aligned}
d\left(x_{m(k)}, x_{n(k)}\right) \leq & d\left(x_{m(k)}, x_{m(k)+1}\right)+d\left(x_{m(k)+1}, x_{n(k)+1}\right)+d\left(x_{n(k)+1}, x_{n(k)}\right) \\
& \leq 2 d\left(x_{k}, x_{k-1}\right)+u^{-1}\left(v\left(d\left(x_{m(k)}, x_{n(k)}\right)\right)\right) .
\end{aligned}
$$

Since $v$ is continuous from the right and $u^{-1}$ is continuous, then from (2.5), (2.7) and (2.9), we get (note that $v(\epsilon)<u(\epsilon)$ )

$$
\epsilon \leq u^{-1}(v(\epsilon))<\epsilon,
$$

a contradiction. Then $\left\{x_{n}\right\}$ is a Cauchy sequence.

Now suppose that (c) holds. To prove that $\left\{x_{n}\right\}$ is a Cauchy sequence let us, on the contrary, assume that $\limsup _{m, n \rightarrow \infty} d\left(x_{m}, x_{n}\right)>0$. By the triangle inequality and using (2.11),

$$
\begin{gathered}
d\left(x_{m}, x_{n}\right) \leq d\left(x_{m}, x_{m+1}\right)+d\left(x_{m+1}, x_{n+1}\right)+d\left(x_{n+1}, x_{n}\right) \\
\leq d\left(x_{m}, x_{m+1}\right)+u^{-1}\left(v\left(d\left(x_{m}, x_{n}\right)\right)\right)+d\left(x_{n+1}, x_{n}\right),
\end{gathered}
$$

for each $m, n \in \mathbb{N}$. Then for each $m, n \in \mathbb{N}$, we have

$$
0 \leq d\left(x_{m}, x_{n}\right)-u^{-1}\left(v\left(d\left(x_{m}, x_{n}\right)\right)\right) \leq d\left(x_{m}, x_{m+1}\right)+d\left(x_{n+1}, x_{n}\right) .
$$


From (2.5), we get

$$
\lim _{m, n \rightarrow \infty} d\left(x_{m}, x_{n}\right)-u^{-1}\left(v\left(d\left(x_{m}, x_{n}\right)\right)\right)=0 .
$$

From (c) we deduce that $\left\{d\left(x_{m}, x_{n}\right)\right\}$ has a bounded subsequence. Let us denote $\lim _{k \rightarrow \infty} d\left(x_{m_{k}}, x_{n_{k}}\right)=r>0$. Then from (2.13) and using the continuity of $u$, we get that

$$
\lim _{k \rightarrow \infty} u\left(d\left(x_{m_{k}}, x_{n_{k}}\right)\right)=u(r) \geq v(r),
$$

a contradiction. This shows that $\left\{x_{n}\right\}$ is a Cauchy sequence.

Since $X$ is a complete metric space then $\left\{x_{n}\right\}$ is convergent. Let $\lim _{n \rightarrow \infty} x_{n}=\bar{x}$. From our assumption on $T$, we have

$$
u\left(d\left(x_{n}, T \bar{x}\right)\right)=u\left(d\left(T x_{n-1}, T \bar{x}\right)\right) \leq v\left(d\left(x_{n-1}, \bar{x}\right)\right) .
$$

Letting $n \rightarrow \infty$ and using continuity of $u$ and continuity of $v$ at 0 ,

$$
u(d(\bar{x}, T \bar{x})) \leq v(0)=0,
$$

which implies $u(d(\bar{x}, T \bar{x}))=0$, that is, $T \bar{x}=\bar{x}$.

To prove the uniqueness of the fixed point, let us suppose that $\bar{x}$ and $\bar{y}$ are two fixed points of $T$. Then, we have

$$
u(d(\bar{x}, \bar{y}))=u(d(T \bar{x}, T \bar{y})) \leq v(d(\bar{x}, \bar{v})),
$$

and so $d(\bar{x}, \bar{v})=0$. Thus $\bar{x}=\bar{y}$.

Remark 1. Let $u(t)=\psi(t)$ and $v(t)=\psi(t)-\phi(t)$ for each $t \in[0, \infty)$ where $\psi, \phi$ : $[0, \infty) \rightarrow[0, \infty)$ are continuous and increasing function such that $\psi(t)=\phi(t)=0$ if and only if $t=0$. Then from Theorem 4 we get immediately the above mentioned result of Dutta and Choudhury.

Now we get the following fixed point theorem of integral type due to Branciari [2].

Corollary 1. Let $(X, d)$ be a complete metric space and let $k \in[0,1), T: X \rightarrow X$ be a mapping such that for each $x, y \in X$,

$$
\int_{0}^{d(f x, f y)} \varphi(t) d t \leq k \int_{0}^{d(x, y)} \varphi(t) d t,
$$

where $\varphi:[0, \infty) \rightarrow[0, \infty)$ is a Lebesgue-integrabel mapping which is summable, non-negative, and such that for each $\epsilon>0, \int_{0}^{\epsilon} \varphi(t) d t>0$. Then $T$ has a unique fixed point $\bar{x} \in X$ such that $\lim _{n \rightarrow \infty} T^{n} x=\bar{x}$, for each $x \in X$.

Proof. Let $u(t)=\int_{0}^{t} \varphi(x) d x$ and $v(t)=k u(t)$ for each $t \in[0, \infty)$ and apply Theorem 4.

The following result (due to Browder [3]) is another consequence of our main result. 
Corollary 2. Let $(X, d)$ be a complete metric spaceand let $T: X \rightarrow X$ be a mapping such that for each $x, y \in X$,

$$
d(T x, T y) \leq \psi(d(x, y)),
$$

where $\psi:[0, \infty) \rightarrow[0, \infty)$ is non-decreasing and continuous from the right. Then $T$ has a unique fixed point $\bar{x} \in X$ such that $\lim _{n \rightarrow \infty} T^{n} x=\bar{x}$, for each $x \in X$.

Corollary 3 ([7]). Let $(X, d)$ be a complete metric space and let $T: X \rightarrow X$ be a mapping such that for each $x, y \in X$,

$$
d(T x, T y) \leq \alpha(d(x, y)) d(x, y),
$$

where $\alpha:[0, \infty) \rightarrow[0,1)$ satisfying

$$
\alpha\left(t_{n}\right) \rightarrow 1 \Rightarrow t_{n} \rightarrow 0 .
$$

Then $T$ has a unique fixed point $\bar{x} \in X$ such that $\lim _{n \rightarrow \infty} T^{n} x=\bar{x}$, for each $x \in X$.

Proof. Let $u(t)=t$ and $v(t)=\alpha(t) t$ and apply Theorem 4 (note that $u$ and $v$ satisfy (c)).

\section{ACKNOWLEDGEMENTS}

The first author was partially supported by the Center of Excellence for Mathematics, University of Shahrekord, Iran and by a grant from IPM (No. 91470412), while the work of the second author was supported by a grant of the Romanian National Authority for Scientific Research, CNCS-UEFISCDI, project number PNII-ID-PCE2011-3-0094.

\section{REFERENCES}

[1] Y. I. Alber and S. Guerre-Delabriere, "Principle of weakly contractive maps in Hilbert spaces," in New results in operator theory and its applications: the Israel M. Glazman memorial volume, ser. Oper. Theory, Adv. Appl., I. Gohberg, Ed. Basel: Birkhäuser, 1997, vol. 98, pp. 7-22.

[2] A. Branciari, "A fixed point theorem for mappings satisfying a general contractive condition of integral type," Int. J. Math. Math. Sci., vol. 29, no. 9, pp. 531-536, 2002.

[3] F. E. Browder, "On the convergence of successive approximations for nonlinear functional equations," Nederl. Akad. Wet., Proc., Ser. A, vol. 71, pp. 27-35, 1968.

[4] L. B. Ćirić, "A generalization of Banach's contraction principle," Proc. Am. Math. Soc., vol. 45, pp. 267-273, 1974.

[5] L. B. Ćirić, "Multi-valued nonlinear contraction mappings," Nonlinear Anal., Theory Methods Appl., Ser. A, Theory Methods, vol. 71, no. 7-8, pp. A, 2716-2723, 2009.

[6] P. N. Dutta and B. S. Choudhury, "A generalisation of contraction principle in metric spaces," Fixed Point Theory Appl., vol. 2008, p. 8, 2008.

[7] M. A. Geraghty, "On contractive mappings," Proc. Am. Math. Soc., vol. 40, pp. 604-608, 1973.

[8] J. Jachymski, "Equivalent conditions and the Meir-Keeler type theorems," J. Math. Anal. Appl., vol. 194, no. 1, pp. 293-303, 1995.

[9] J. Jachymski, "Remarks on contractive conditions of integral type," Nonlinear Anal., Theory Methods Appl., Ser. A, Theory Methods, vol. 71, no. 3-4, pp. A, 1073-1081, 2009. 
[10] M. S. Khan, M. Swaleh, and S. Sessa, "Fixed point theorems by altering distances between the points," Bull. Aust. Math. Soc., vol. 30, pp. 1-9, 1984.

[11] W. A. Kirk, "Fixed points of asymptotic contractions." J. Math. Anal. Appl., vol. 277, no. 2, pp. 645-650, 2003.

[12] Z. Liu, W. Sun, S. M. Kang, and J. S. Ume, "On fixed point theorems for multivalued contractions," Fixed Point Theory Appl., vol. 2010, p. 18, 2010.

[13] A. Meir and E. Keeler, "A theorem on contraction mappings," J. Math. Anal. Appl., vol. 28, pp. 326-329, 1969.

[14] S. B. j. Nadler, "Multi-valued contraction mappings," Pac. J. Math., vol. 30, pp. 475-488, 1969.

[15] B. E. Rhoades, "Some theorems on weakly contractive maps," Nonlinear Anal., Theory Methods Appl., vol. 47, no. 4, pp. 2683-2693, 2001.

Authors' addresses

A. Amini-Harandi

Department of Mathematics, University of Shahrekord,, Shahrekord, 88186-34141, Iran

E-mail address: aminih_a@yahoo.com

\section{A. Petruşel}

Department of Mathematics, Babeş-Bolyai University Cluj-Napoca, Kogălniceanu Street No.1, 400084,

Cluj-Napoca, Romania

E-mail address: petrusel@math.ubbcluj.ro 